\title{
Endoürolojide Simülasyon
}

\author{
Eşref Oğuz Güven, Taha Numan Akyol
}

Ankara Abdurrahman Yurtarslan Onkoloji Eğitim ve Araştırma Hastanesi, Üroloji Kliniği, Ankara

\section{Giriş}

Son yıllarda cerrahi tekniklerdeki gelişmeler, endoskopik, Slaparaskopik ve robotik cerrahi gibi el göz koordinasyonu gerektiren yöntemlerin ağırlık kazanmasıyla ameliyathane öncesindeki eğitimler önem kazanmıştır. Bu eğitimler ile komplikasyonlarda azalma, zamanın verimli kullanılması, güvenli cerrahi prosedürler geliştirilmesi ve maliyetlerin düşürülmesi planlanmıştır. Bu amaçla simülasyon teknikleri kullanılmaya başlanmıştır. Simülasyon eğitimi ilk olarak pilotlarda ve askeri çevrelerde kullanılmıştır. Tarihte ilk kullanım yerinin Roma askerleri olduğu bildirilmektedir (1). Tıpta ilk 16. yy döneminde 'phantom' adı verilen plastik maketler üzerinde, anne ve bebek ölümlerini azaltmak amacı ile obstetrik becerilerin eğitimi amaçlı kullanıldığı düşünülmektedir. Yıllardır tıp alanında hayvan modelleri, kadavralar ve çeşitli materyaller üzerinde simülasyon teknikleri uygulanmaktadır (2).

Simülasyon bazlı eğitimler çeşitli kliniklerde olduğu gibi üroloji alanında da kullanılmaktadır ve 2008 yılındaki "Residency Review Committee" deklarasyonunda Amerika' daki tüm cerrahi pratik eğitimlerde 'simülasyon ve yetenek laboratuarları'nı zorunlu kılmıştır. Simülasyon eğitiminin cerrahi pratikteki performası artırdığına yönelik çok sayıda çalışma bulunmaktadır (3). İngiltere'de 'SIMULATE' adlı pratik eğitim bazlı ulusal simülasyon programı geliştirilmiş ve online olarak bu sistem cerrahi pratikte kullanılmaktadır (4-6).

Bu çalışmada da endoürolojide simülasyonun kullanımının araştırılması ve bu konudaki çalışmaların toparlanması amaçlanmıştır.

\section{Simülasyon Eğitiminin Komponentleri}

Simülasyon eğitiminde kullanılan simülatörler basit bir alet olabileceği gibi kurgulanan olaya cevap verebilen kompleks yapılar da olabilir. Simülatörün verdiği cevaba göre düşük, orta ve yüksek dereceli simülatörler olabilmektedir. Teknolojinin artmasıyla sistemin oluşturduğu kurgunun inandırıcılığı artarken maliyeti de artmaktadır. Simülatörler mekanik simülatörler şeklinde olabileceği gibi sanal gerçeklik içeren simülatörler, hibrid simülatörler veya insan kadavrası ve hayvan modellerini içeren tarzda da olabilmektedir. $\mathrm{Bu}$ simülatörlerinin hepsinin avantajları ve dezavantajları bulunmaktadır. İleri teknoloji içermeyen simülatörler bilgisayar tarafından yönetilmeyen eğitsel amaçla kullanılan simülatörlerdir. Üç boyutlu organ modelleri (trainingaids), temel plastik mankenler (fizik muayene becerileri, sütür atma eğitimi amaçlı kullanılan), insan kadavrası ve hayvan modelleri (anatomi ve fizyoloji eğitiminde kullanılan) şeklindedir. Bu modeller ucuz, geri dönüşümü olmayan doğruluğu düşük modellerdir. İleri teknoloji içeren simülasyonlar bilgisayar tarafından kontrol edilmektedir. Görüntüye dayalı simülatörler (Screen-basedsimulation) ve sanal gerçeklik (Virtual Reality) simülatörleri buna örnektir. Sanal gerçeklik modelinde bilgisayar kontrollü gerçek ortama en yakın şekilde belli bir kurgu planlanmış erişkin boyutlarında manken kullanılarak model üzerinde eğitim çalışmaları yapılmaktadır, bu modellerde kullanıcı geri dönüşü vardır ancak maliyeti yüksektir. Hibrid sistemlerde, mekanik ve sanal gerçeklik içeren simülatörler birlikte kullanılarak inandırıcılık artırılmıştır (7). Simülasyonların her tipinde mutlaka olması gereken özellik "fidelity" olarak bilinen "aslına uygunluk" kriteridir. Bu kriterle simülasyon gerçeğe ne kadar yakın ve benzer olursa, katılımcının izlediği yollara uygun simülatör cevabı sayesinde öğrenilen bilgi gerçek durumlara o kadar transfer olabilmektedir $(8,9)$. Bu özelliğin dişında simülatörün amac1, müfredata entegre olabilmesi, geribildirim (feedback) vermesi, klinik varyasyonlara uygunluk gösterebilmesi, beceri kazanma ve hatırlamaya etkisi gibi 12 ayrı özelliğe sahiptir $(11,12)$. Ahmed ve arkadaşları da ürolojide simülasyonun etkisini araştırmışlar ve öğrenmeye katkı sağlayacak ipuçlarını 5 başlık altında toplamışlardır:

- Kişi: simülasyon eğitimini veren kişinin konuya hakimiyeti

- Yer: eğitimin yapıldığı modelin veya yerin gerçek iş ortamiyla benzerliği

- Maliyet: yeterli finansmanın varlığı

- Pozisyon: simülasyonun cerrahi eğitim içindeki pozisyonu ve müfredata entegrasyonu

- Ürünler: simülatörün kendisi $(3,10,12)$

\section{Endoürolojide simülasyon}

Ürolojide simülasyon eğitimi sıklıkla endoürolojik (sistoskopi, transüretral prostat rezeksiyonu, üreteroskopi), laparoskopik (nefrektomi, prostatektomi) ve robotik cerrahide kullanılmaktadır. Sıklıkla sanal gerçeklik "Virtual Reality" simülatörler tercih edilmektedir. Ancak bu simülatörlerin doğruluğunu ispatlayacak veya başarısını gösterecek objektif kriterler bulunmamaktadır. Çoğunlukla katılımcılar tarafından uygulanan anketler ile metodlar onaylanmaktadır. Objektif bir değerlendirmede ise simülatörün yeni kat1lımcı ve uzman katılımcı arasındaki farkı göstermesi, alınan 
eğitimin gerçek performansa katkısının olması ve öğrenilmesi istenen işlem için altın standart olması önerilmektedir. Üroloji alanında simülasyonun katkısını gösteren 3 büyük çalışma bulunmaktadır. Schout ve arkadaşları endoürolojide simülasyonla ilgili derlemelerini 2008 yılında yayınlamışlardır. Ahmed ve arkadaşları da benzer bir çalışmayı 2011'de yayınlamışlar ancak tüm simülatörlerden bahsetmemişlerdir. Son olarak da Abboudi ve arkadaşları robotik ürolojik cerrahi üzerine simülasyonun etkisini değerlendirmişlerdir $(10,13,14)$. Bu çalışmaların çoğunda özellikle yeni katılımcılarda simülatörün pratik performansı artırdığı hayvan modelleri üzerinde yapılan pratiklerde gösterilmiştir.

\section{Simülatör Modelleri}

Son zamanlarda endoürolojide sanal gerçeklik (VR) modelinin simülasyonda kullanımı artmıştır. Bu modelde cerrahi bir senaryo oluşturularak endoskopik operasyon yetenekleri geliştirilmektedir. Endoürolojide hemen hemen tüm operasyonlara yönelik simülasyon eğitim modelleri bulunmaktadir.

\section{Sistoüreteroskopi}

URO Mentor Simbionix firması tarafından üretilen endoürolojide tanı ve tedavi işlemlerinde eğitim ve uygulama olanaklarını sağlayan bir simülatördür. Gerçeğe en uygun prosedür oluşturularak anatomi ve koordinasyon becerilerinin sağlanması amaçlanmıştır. Çalışma kanalları içine gerçek takım takılmasını sağlayarak sert, esnek sistoskopi ve üreteroskopi, pratik temel beceri, taş çıkarma, litotripsi, darlıkların kesilmesi, biyopsi alınması, floroskopi ve C-kol kontrollü gerçek zamanlı simülasyon gibi operasyonlara olanak sağlamaktadır (Resim 1). İsveç'te 2013 de yapılan bir çalışmada 4.sınıf tıp öğrencilerine URO Mentor ile simülasyon yaptırılmış ve sezon sonu cerrahide teorik sınav yapılmış. Kız öğrencilerde simülatör performansı ile sınav sonuçları arasında anlamlı ilişki göze çarpmış ( $\mathrm{r}=-0.22$, p=0.04) (15). Yine başka bir çalışmada acemi ve uzman ürologlara URO Mentor eğitimi verilmiş ve travma, operasyon süresi, kanama gibi parametrelere bakılmış. Eğitimi alan acemi ürologlarda performansta orta derecede iyileşme gözlenmiştir (16).

\section{Transüretral Prostat Rezeksiyonu (TURP)}

Siklıkla Uro Trainersimülatörü (Karl Storz, Almanya) ve UW TURP Simülatör (Washington Üniversitesi) kullanılmaktadır (17-19). Bunlarla ilgili çalışmalarda performansta başarılı oldukları gözlenmiştir. Simbionix firmasının yeni geliştirdiği TURPSim ${ }^{\mathrm{TM}}$ simülatörü ile transüretral prostatektomide simülasyon eğitimi araştırılmış, simülatörü kullanan 38 ürolog ile global oran skalası (GRS) eğitim öncesi ve sonrasında doldurulmuş ve farkları kaydedilmiştir (17). Bu simülatörde prostat anatomisi ve morfolojisi canlandırılmış ve rezeksiyona olanak sağlanmıştır (Resim 2). Prostat bezi ve kapsül rezeksiyonu, kan kaybı, koagülasyon miktarı, eksternal sfinkter, mesane boynu, verumontarum ve üreteral orifis yaralanmalarına göre skala doldurulmaktadır. Skorlama sonucunda istenmeyen yan etkilerde eğitimden sonra anlamlı bir azalma cerrahi tecrübede artış olarak değerlendirilmiştir. Bu çalışma sonucunda sanal gerçeklik çalışması olan TURPSim $^{\mathrm{TM}}$ simülatörünün eğitimde ve deneyimde faydalı olduğu görüşü benimsenmiştir (17) (Tablo 1). 'American Urological Association' (AUA) 2012'de Samuel Vine ve arkadaşlarının sunduğu 2 ayrı çalışmada acemi uzmanlara TURPSim $^{\mathrm{TM}}$ eğitimi verilerek dakikada rezeke edilen prostat miktarında artış ve kapsül perforasyonun da azalma gözlendiği bildirilmiştir $(20,21)$.

\section{Perkütan nefrolitotomi}

PERC Mentor ${ }^{\mathrm{TM}}$ gerçek zamanlı floroskopi altında böbrek toplayıcı sistemlerine perkütan girişi sağlamaktadır. SimbionixPERC Mentor ${ }^{\mathrm{TM}}$ aşağıdaki becerilerin kazanılmas1na yardımcı olur:

- El- göz koordinasyonu

- Floroskopi ile 2 boyutlu görüntülenen yapıların 3 boyutlu şekilde görselleştirilmesi

- Floroskopik görüntü manipülasyonu

- Araçlar ve kılavuz tel ile manipülasyon

- İdeal giriş elde etmek için C-kol manipülasyonu

- Değişen boyut ve uzunluklardaki iğnelerin kullanımı

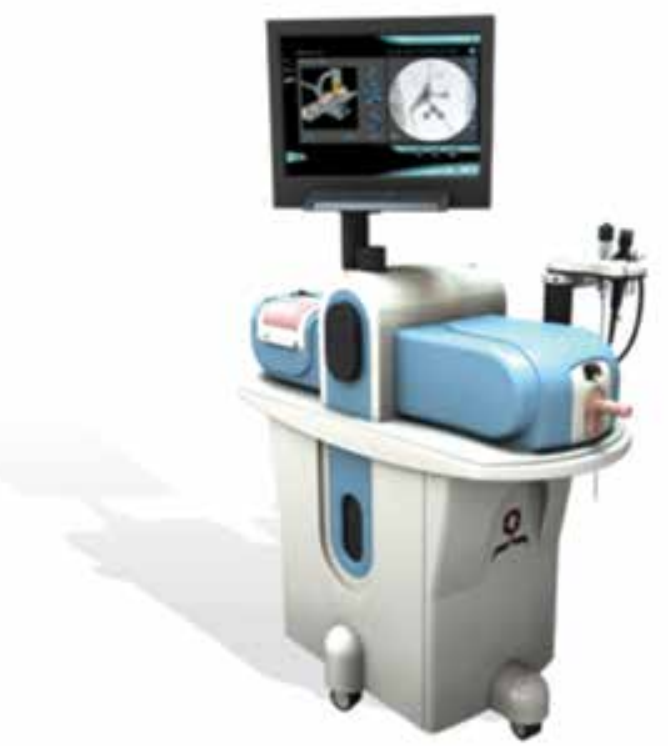

Resim 1: URO Mentor

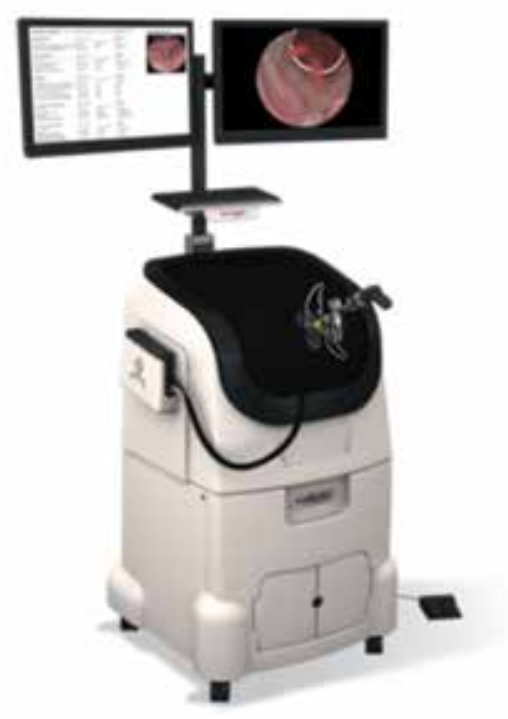

Resim 2: TURPSim ${ }^{\mathrm{TM}}$ simülatörü 
ENDOÜROLOJIDE SIMÜLASYON

Tablo 1: Endoürolojideki simülatörler

\begin{tabular}{llll}
\hline İşlem & Simülatör tipi & Simülatör adi & Firma \\
\hline Sistoskopi & VR & URO Mentor & Simbionix \\
Üreteroskopi & VR & URO Mentor & Simbionix \\
TURP & VR & UroTrainer & Karl Storz \\
& UW TURP & Washington Uni. & \\
TURBT & VR & Simbionix & Simbionix \\
PCNL & VR & URO Mentor & Simbionix \\
Laparaskopi & VR & PERC Mentor & Simbionix \\
& MIST VR® & Lap Mentor & \\
& LSW 3.0 & Mentice & \\
& MIST 2 & SurgicalScience & \\
& Xitact LS500® & & \\
& ProMIS & Mentice & \\
& Procedicus MIST & Haptica & \\
& VIRGY & Mentice & \\
& LapSim ${ }^{\circledR}$ & SurgicalScience & \\
\hline
\end{tabular}

PERC Mentor ${ }^{\mathrm{TM}}$ ile yapılan bir eğitim çalışmasında 21 ürolog tarafından perkütan giriş yapılmış ve GRS skorlaması doldurulmuştur. Eğitim sonrası toplam operasyon süresinde ve kontrast madde kullanımında anlamlı bir azalma olduğu gösterilmiştir (sırasıyla p=0.03, p=0.02) (22). Yine 36 ürolog tarafından yapılan başka bir çalışmada da operasyon süresi, kontrast madde kullanımı, radyasyon dozu ve kanama miktarında anlamlı bir azalma olduğu gözlenmiştir $(\mathrm{p}<0.01)(23)$ (Resim 3).

\section{Laparaskopi}

Lap Mentor ${ }^{\mathrm{TM}}$ (Simbionix, Cleveland, USA) gerçek intraabdominal görüntü olanağı sağlayarak, kesme, tutma, organlara pozisyon verme, sütür, koterizasyon ve kolesistektomi gibi operasyonlara olanak sağlamaktadır. Ayrıca spesifik operasyon olanağı sağlayamayan, temel laparoskopik yaklaşım ve sütür teknikleri çalışma imkanı sunan video simü- lasyon sistemlerine verilebilecek diğer örnekler Minimally Invasive Surgical Trainer in Virtual Reality (MIST VR®; Mentice, Gothenburg, Sweden), LSW 3.0 (Surgical Science of Stockholm), MIST 2 ve Xitact LS500®'dir. LapSim ${ }^{\circledR}$ (Surgical Science, Gothenburg, Sweden) MIST VR®'e göre daha komplex yapıdadır, kanama, deformasyon özellikleri içermekte ve 3 ayrı zorluk derecesine sahiptir (24). LapSim ${ }^{\circledR}$ simülatörü kullanılarak operasyon süresinde azalma ve pratik beceride artış gösterilmiştir $(25,26)$ (Resim 4). Diğer taraftan MIST VR ise basit laparaskopi manevralarının öğrenilebildiği portabl, ucuz ve kolay ulaşılabilir bir simülatördür. Bu simülatörlerin de çalışmalar sonucunda öğrenme eğrisini hızlandırdığı görülmüştür $(27,28)$ (Resim 5).

Dokunma hissinin olduğu yeni gelişen sistemler Lap Mentor (Simbionix), ProMIS (Haptica), Procedicus MIST (Mentice Medical), ve VIRGY (Swiss Federal Institute of Technology) dir (29). Sonuç olarak Lap Mentor en gelişmiş
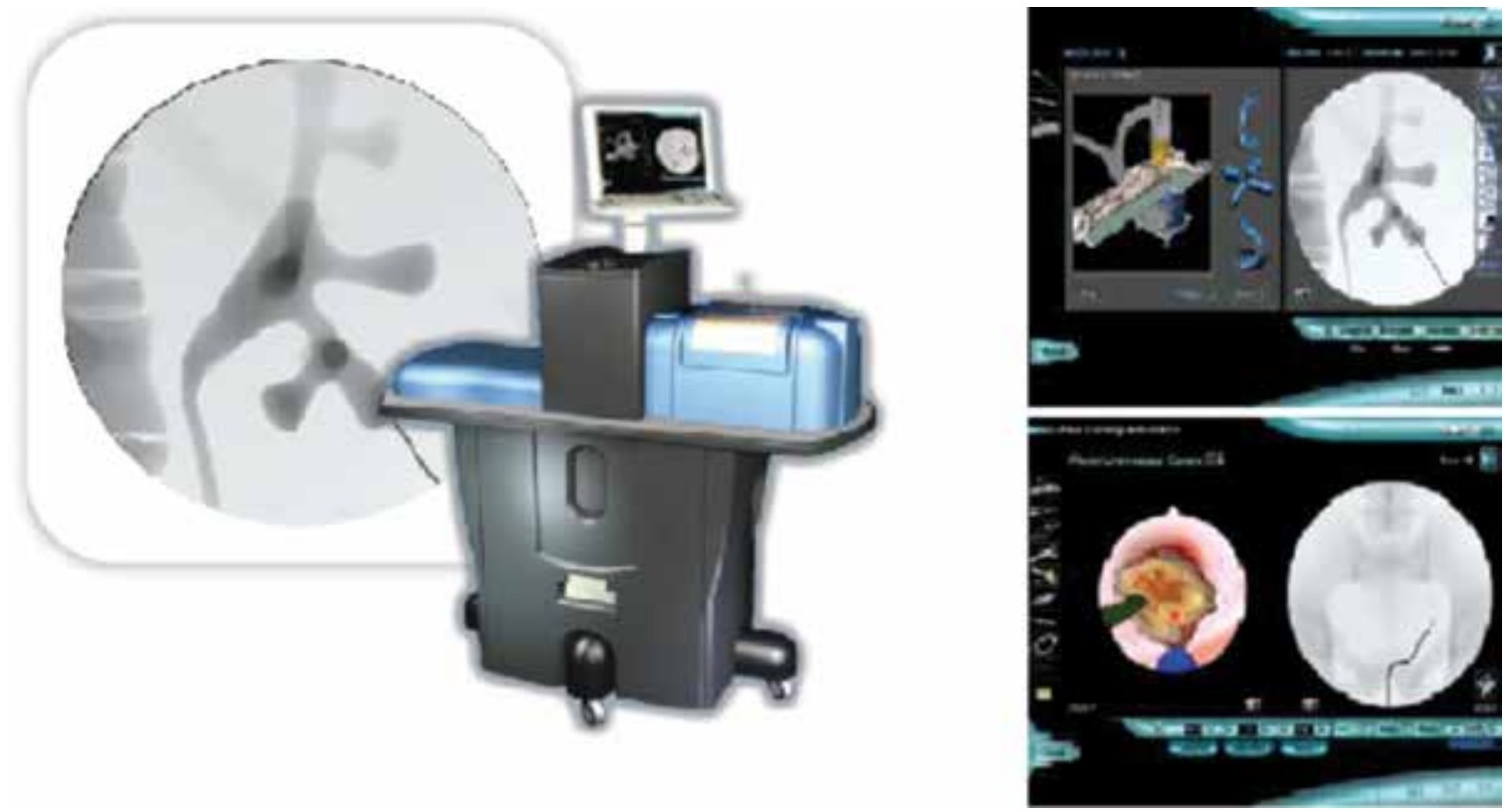

Resim 3: PERC Mentor, floroskopi altındaki manipülasyonlar ve endoürolojiksimülasyon görüntüsü 


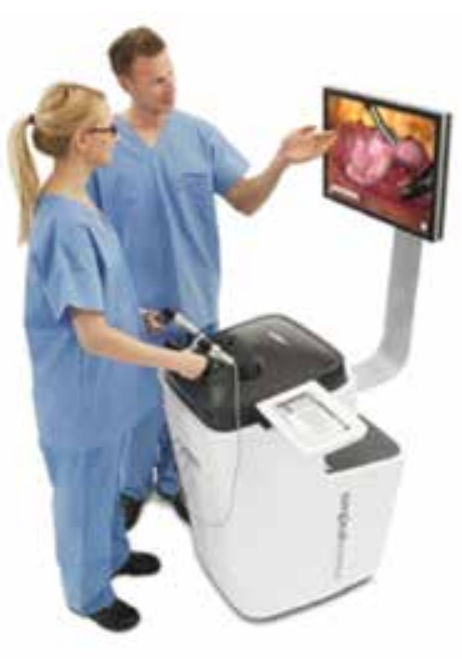

Resim 4: Lap Sim ${ }^{\circledR}$

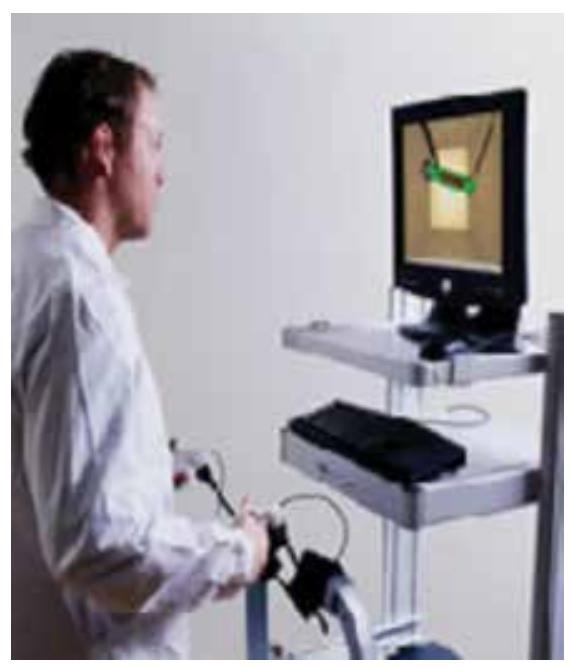

Resim 5: MIST VR

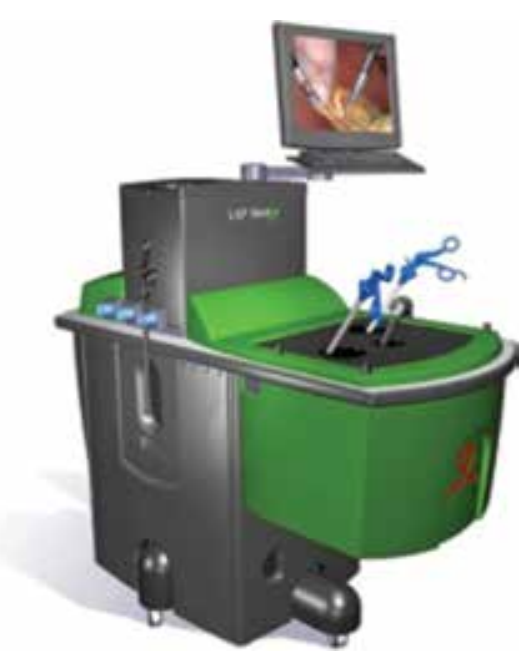

Resim 6: Lap Mentor
VR simülatör jenerasyonudur. Basit işlemler, sütür teknikleri, belirli prosedür uygulamaları, basitten (kolesistektomi, herni onarımı) komplike (gastrik bypass, histerektomi, kolektomi) laparoskopik cerrahilere kadar farklı alanlarda pratik uygulama olanağı sunmaktadır. VR simülasyonunun oluşturulmasında in vivo laparaskopik görüntüler ve Manyetik Rezonans (MRI) görüntüleri kullanılmaktadır (30). Pek çok çalışma laparaskopide simülasyonun öneminden bahsetmektedir. Matsuda ve arkadaşlarının 92 ürolog ile yaptıkları çalışmada uzmanlar deneyim becerilerine göre gruplara ayrılmış ve Lap Mentor ile deneyimi fazla olan grupta becerilerin klinik olarak belirgin şekilde arttığı gözlenmiştir (31) (Resim 6).

Literatür tarandığında endoürolojide simülatör teknolojisinin üretiminde ve araştırılmasında 13 ayrı firmanın bulunduğu gözlenmiştir. Merkezi Kanada, Montreal'de bulunan CAE Healthcare Inc. 2010 yılından sonra oluşmuş ve önemli markası VIMEDIX ile ortaya çıkmıştır. HapticaProMIS ile merkezi İsveç, Göteborg'da olan Mentice ABise MIST VR, Xitact LS500® ve Procedicus MIST ile laparaskopide simülasyona katkıda bulunmaktadırlar. Merkezi Cleveland, ABD'de bulunan Simbionix bu sektördeki en eski firmalardan biridir ve endoürolojik simülasyonda en etkili VR simülatörlerin de üreticisidir. SimSurgery Norveç menşeylidir ve laparaskopik nefrektomi eğitiminde simülatörür etmektedir. SurgicalScienceLapSim ile yine laparoskopide hizmete sunulmuştur (32).

\section{Sonuç}

Simülasyon teknolojisi uzun zamandır uygulanmakta olan endoürolojinin gelişmesiyle birlikte bu alanda da kullanımı başlayan bir sistemdir. Klinisyenin yetenek ve becerilerini zararsız bir ortamda geliştirmesine olanak sağlayarak gerçek operasyon öncesi tecrübe kazanmasını sağlamaktadır. Bu şekilde operasyon sırasında gelişebilecek istenmeyen yan etkilerin düşürüldüğü pek çok çalışmada kanıtlanmıştır. Teknolojinin ilerlemesiyle beraber simülasyon teknolojisi de gelişmiştir. Laparoskopik cerrahi eğitiminde kullanılan fiziksel simülatörler uygulaması kolay ve maliyeti düşüuk sistemlerdir, dokunma ve derinlik hissi bulunmaktadır. Bilgisayar temelli video sistemlerde ise, teknik öğretiminin ötesinde operasyonların sanal ortamda yapılmasına olanak sağlamaktadır. Ancak maliyeti kapasitesiyle orantılı artmaktadır. Simülatörler ayrıca klinisyenin becerisinin test edilmesine olanak da sağlamaktadır.

\section{Kaynaklar}

1. Helmreich RL, Merrit AC, Wilhem JA. The evalution of crew resource management training in commercial aviation. Int J AviatPsychol 9:19-32, 1999.

2. Al-Kadı AS, Donnon T. Using simulation to improve the cognitive and psychomotor skills of novice students in advanced laparoscopic surgery: A-meta analysis. 35 suppl 1:47-55, 2013.

3. Brewin J, Ahmed K, Challacombe B. An update and review of simulation in urological training. Int J Surg 12(2):103-8, 2014.

4. Forster JA, Browning AJ, Paul AB, Biyani CS. Surgical simulators in urological training- views of UK Training Programme Directors. BJU Int 110(6):776-8, Sept 2012.

5. Ahmed K, Amer T, Challacombe B. How to develop a simulation programme in urology. BJU Int 108(11):1698702, Dec 2011.

6. Vassiliou MC, Dunkin BJ, Marks JM. FLS and FES: comprehensive models of training and assessment. Surg Clin North Am 90(3):535-58, Jun 2010.

7. Gardner R. Simulation and simulator technology in obstetrics and gynecology. Obstet Gynecol Clin North Am 35(1):97-127, 2008

8. Patrik J. Simulation in training: Research and practise. London: Academic Press. 2002; 487-508.

9. Maran NJ, Glavin RJ. Low to High Fidelity Simulation A Continuum of medical education. Med Educ 37:22-28, 2003.

10. Ahmed K, Jawad M, Abboudi M. Effectiveness of procedural simulation in urology: a systematic review. J Urol186(1):26-34, Jul 2011.

11. McGaghie WC, Issenberg SB, Petrusa ER, Acalese RJ. A critical review ossimulation-based medical education research: 2003-2009. Med Educ 44(1):50-63, Jan 2010.

12. Mıdık Ö, Kartal M. Simülasyona dayalı tıp eğitimi. Marmara Medical Journal 23(3): 389-99, 2010. 
13. Schout BM, Heindrix AJ, Scheele F. Update on training models in endourology: a quantative systematic review of the literature between January 1980 and April 2008. Eur Urol 54(6):1247-61, Dec 2008.

14. Abboudi H, Khan MS, Aboumarzouk O. Current status of validation for robotic surgery simulators- a systematic review. BJU Int 111(2): 194-205, Feb 2013.

15. Schlickum M, Fellander TL, Hedman L. Endourological simulator performance in female but not male medical students predicts written examination results in basic surgery. Scand J 47(1): 38-42, 2013.

16. Schout BM, Multijens AM, Hendriks AJ. Acquistion of flexibl cyctoscopyskills on a virtual reality simulator be expert sand novices. BJU Int. 15(2): 234-9, 2010.

17. Zhu HE, Zhang Yİ, Liu J. Virtual reality simulator for training urologist on transurethral prostatectomy. Chin Med J 126(7): 1220-23, 2013.

18. Sweet R, Kowalwvski T, Oppenheimer P. Face, content and construct validity of the University of Washington virtual reality transurethral prostate resection trainer. J Urol 172:1953-57, 2004.

19. Kishore TA, Beddigfield R, Holden T. Task deconstruction facilityes acquistion of transurethral resection of prostate skills on a virtual reality trainer. J Endourol 23:665, 2009.

20. Dutton T, Vine S, McGarth J. Examining the visual control strategies of experts and novices to establish the validity of a novel TURP simulator. AUA, Atlanta, 2012.

21. Vine S, Dutton T, Wilson M. Learning effects of using a TURP simulator: Assessing changes in visual control and performance. AUA, Atlanta, 2012.

22. Zhang Y, Yu CF, Liu JS. Training for percutaneous renal access on a virtualy reality simulator. Chin Med J 126(8): 1528-31, 2013.

23. Papatsoris AG, Shaikh T, Patel D. Use of a virtual reality simulator to improve percutaneous renal access skills: a prospective study in urology Trainees. Urol Int 89: 185190, 2012.
24. Beyer-Berjot L, Aggarwal R. Toward technology supperted surgical training: the potential of virtual simulators in laparascopic surgery. Scan J Urol 102: 221-26, 2013.

25. Larsen CR, Soerensen JL, Grancharov TP. Effect of virtual reality training on laparascopic surgery: randomized controlled trial. BMJ 14: 338, 2009.

26. Ahlberg G, Enochsson L, Gallagher AG. Proficiencybased virtual reality training significant lyreduces the error rate for residents during. Am J Surg 193(6): 797-804, 2007.

27. Wilson MS, Middlebrook A, Sutton C. MIST VR: a virtual reality trainer for laparoscopic surgery assesses performance. Ann R Coll Surg Engl 79(6): 403-4, 1997.

28. Chaudhry A, Sutton C, Wood J. Learning rate for laparoscopic surgical skills on MIST VR, a virtual reality simulator: quality of human-computer interface. Ann R Coll Surg Engl 81: 281-286, 1999.

29. Göktolga Ü, Demir B. Kadın doğum kliniğinde simülasyon. J Turk Soc Obstet Gynecol 7(4): 256-61, 2010.

30. Aggarwal R, Moorthy K, Darzi A. Laparascopic skills training and assessment. Br J Surg 91: 1549-58, 2004.

31. Matsuda T, McDougall EM, Ono Y. Positive correlation between motor analyse data on the Lap Mentor virtual reality laparascopic surgical simulator and the results from video tape assessment of real laparascopic surgeries. J Endourol 26(11): 1506-11, 2012.

32. Vapenstad C, Buzink SN. Procedural virtual reality simulation in minimally invasive surgery. Surg Endosc 27: 364-77, 2013.

Yazışma Adresi:

Eşref Oğuz Güven

Ankara Abdurrahman Yurtarslan Onkoloji Eğitim ve Araştırma

Hastanesi, Üroloji Kliniği, Ankara

Tel: +90533 3916187

e-mail:oguz73tr@yahoo.com 